\title{
'We are a very positive family unit
}

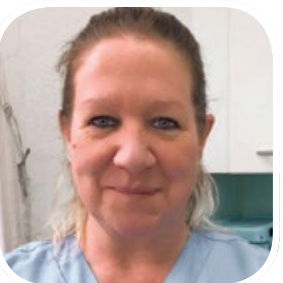

When not in lockdown at home,

Hilary Urry, 51, is practice manager/

dental nurse at Brighton Dental Care.

Hilary qualified as a dental nurse in 1994.

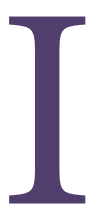

live in Seaford, East Sussex with my partner Paul, his son and son's fiancée. I have two stepchildren and one child of my own. I usually get up at 7.30 am and eat toast and marmalade on the sofa.

My day usually consists of breakfast, shower, dog walk, marking, colouring, gardening and watching 'Spooks'. I am a tutor for the Dental Nurse Network and also for Training 4 Practice. I try not to do any marking at the weekend. I colour using the app 'Happy Colour'; I just find I can lose myself in it and switch off to the outside world. the garden. I think having a garden definitely makes things easier at the moment.

It has been good to spend quality time with my partner and dog, and on the whole, we are a very positive family unit. The pandemic has made me appreciate what I have a lot more and not take things for granted.

In the evenings I colour and watch TV. Paul and I take it in turns to cook, although generally he cooks more than me.

I miss seeing family and friends in person but I have a FaceTime call every week with my sisters and message my best friend every day. When lockdown is over, I look forward to seeing my best friend and giving him a huge hug.

\section{'It has been good to spend quality}

\section{time with my partner and dog.}

\section{The pandemic has made me}

\section{appreciate what I have a lot more.}

At the moment workwise I just do occasional emails as requested by my employer. I remind the dentists who are in triaging calls, via WhatsApp, to run the water lines weekly and change the Alpron, running the taps in line with Legionella requirements.

I was deployed to a GP 'hot hub' in Seaford, but due to a lack of patients needing the service - which is a good thing - I have been temporarily stood down.

Every day I go for a walk with the dog and my partner. I also spend time pottering in

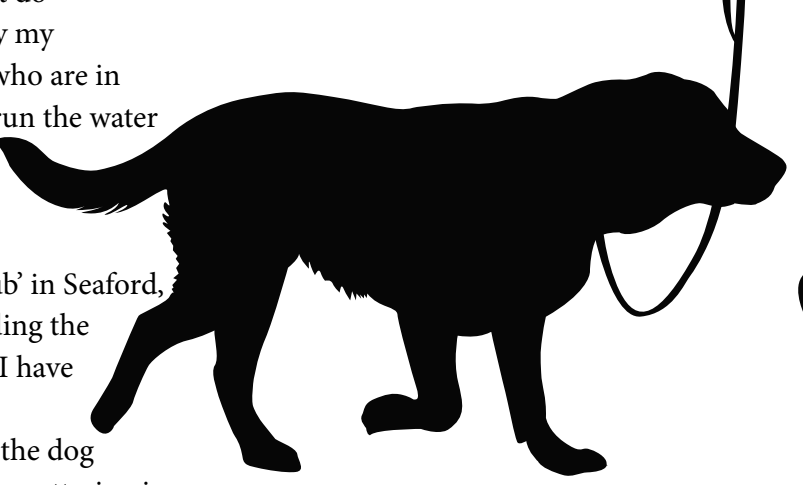

I do miss my colleagues, although we keep in touch weekly through WhatsApp.

Regarding my future career in dentistry, I am slightly apprehensive about the effects of aerosol generating procedures (AGPs) and minimal personal protective equipment (PPE) or time to clean down between patients, due to NHS demands.

I usually go to bed at $11 \mathrm{pm}$ and sleep fairly well, depending on whether Paul is snoring

or not.

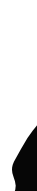

